Bangladesh J. Bot. 50(3): 717-727, 2021 (September) SpecialＤOI: https://doi.org/10.3329/bjb.v50i5.56422

\title{
CHARACTERIZATION OF RPP5CS AND RPOAT FROM RUMEX PATIENTIA L. IN RESPONSE TO SALINITY AND ALKALINITY STRESS
}

\author{
Lina Peng, Lili Sun, Yongqing Xu ${ }^{1}$, Zhenxue CaI ${ }^{1}$, \\ Xu Feng ${ }^{1}$, Fenglan Li ${ }^{1 *}$ and BaOzhong Hu ${ }^{2 *}$ \\ College of Sport Human Sciences, Harbin Sport University, No. 1 Dacheng Road, \\ Nangang District, Harbin 150030, Heilongjiang, China
}

Keywords: Characterization, Rumex patientia, Salinity, Alkalinity

\begin{abstract}
Rumex patientia L. can respond to abiotic stresses and withstand low temperatures. Proline accumulation plays important roles under various abiotic stresses in different plants, specially salinity. P5CS and OAT of plants are key enzymes in the proline synthesis pathway. In the present study, the RpP5cs and $R p O a t$ genes of the proline synthesis pathway in $R$. patientia L. were cloned with full-length cDNAs of 2178 bp and 1401 bp. The expression of RpP5cs and RpOat genes were higher in Russian Щавель Чемпион than Chinese $R$. patientia $\times R$. tianschanicus cv. Rumex under salinity and alkalinity stress over $0-24 \mathrm{hrs}$. These results could provide insights into sequence structure and differential tolerance in many plants.
\end{abstract}

\section{Introduction}

Rumex patientia $\mathrm{L} .(2 \mathrm{n}=10)$ is a vegetable grown in some countries including Turkey and India (Qi et al. 2012). R. patientia can respond to temperature and various stresses (Namgail et al. 2007, Singh et al. 2013). The transcriptome of Rumex patientia L. was analyzed and cultivated in cold regions during cold stress (Liu et al. 2017). Variable environments could cause negative effects on growth and productivity, especially salinity and alkalinity stress (Li et al. 2015). Proline is an important osmotic regulator when plants respond to environment change. Usually plants are influenced to external stresses (Peng et al. 2019, 2020), all kinds of osmoregulation substances, such as proline, betaine, and monosaccharides which will accumulate to deal with the stress through osmotic adjustment (Serrano 1996). Proline accumulation is influenced by drought, salinity, metals, and biotic stresses (Kavi et al. 2005, Wang et al. 2007). In plants, the proline synthesis pathway can be divided in two: glutamate and ornithine pathway (Fig. 1) (Adams and Frank 1980, Delauney et al. 1993, Kavi et al. 2005). In the glutamate pathway, proline is generated by two reduction reactions of glutamate catalyzed by the enzymes $\triangle$-pyrroline-5carboxylate synthase (P5CS) and pyrroline-5-carboxylate reductase (P5CR). P5CS (EC2.7.2.11) catalyzes glutamate via the phosphorylation process, which also reduces the product to form glutamate semi-aldehyde (GSA) (Hu et al. 1992). In the ornithine pathway of proline synthesis, ornithine is catalyzed to the product pyrroline-5-carboxylate via ornithine-delta-aminotransferase (OAT), the OAT(EC2.6.1.13) enzyme is present in mitochondria (Verbruggen and Hermans 2008).

P5CS is a key, bifunctional enzyme (Hu et al. 1992) and the rate-limiting enzyme (Kavi et al. 2005) for proline production via the glutamate pathway in plants. The P5cs gene was cloned from many species, e.g. Arabidopsis thaliana (Thompson et al. 1997), Brassica napus (Kubala et al. 2015), Phaseolus vulgaris (Chen et al. 2013), Medicago truncatula (Armengaud et al. 2004). The

*Author for correspondence: <bzhu@neau.edu.cn>; <lflan715@163.com>. ${ }^{1}$ College of Life Science, Northeast Agricultural University, No. 600 Changjiang Road, Xiangfang District, Harbin 150030, Heilongjiang, China. ${ }^{2}$ Harbin University, No. 109 Zhongxing Road, Nangang District, Harbin, 150086, Heilongjiang, China. 
expression of P5cs genes is induced via various abiotic stresses, e.g., the $0 s P 5 c s 1$ gene is expressed in response to salinity, drought, and cold stress (Igarashi et al. 1997). Over-expression of P5cs genes in Arabidopsis thaliana (Chen et al. 2013), wheat (Vendruscolo et al. 2007), and chickpea (Ghanti et al. 2011) resulted increased proline production and salt tolerance. The ornithine-delta-aminotransferase encoded by the delta-OAT (Oat) gene is the key enzyme for the synthesis of proline from the pathway using ornithine as the precursor (Kavi Kishor et al. 2005). Over-expression of AtOat in tobacco increased proline production and drought tolerance (Nancy et al. 2002), over-expression of Oat in rice increased salt tolerance (Wu et al. 2003), and molecular and functional analyses of OAT were shown in glutamine biosynthesis during pine germination (Canas et al. 2008).

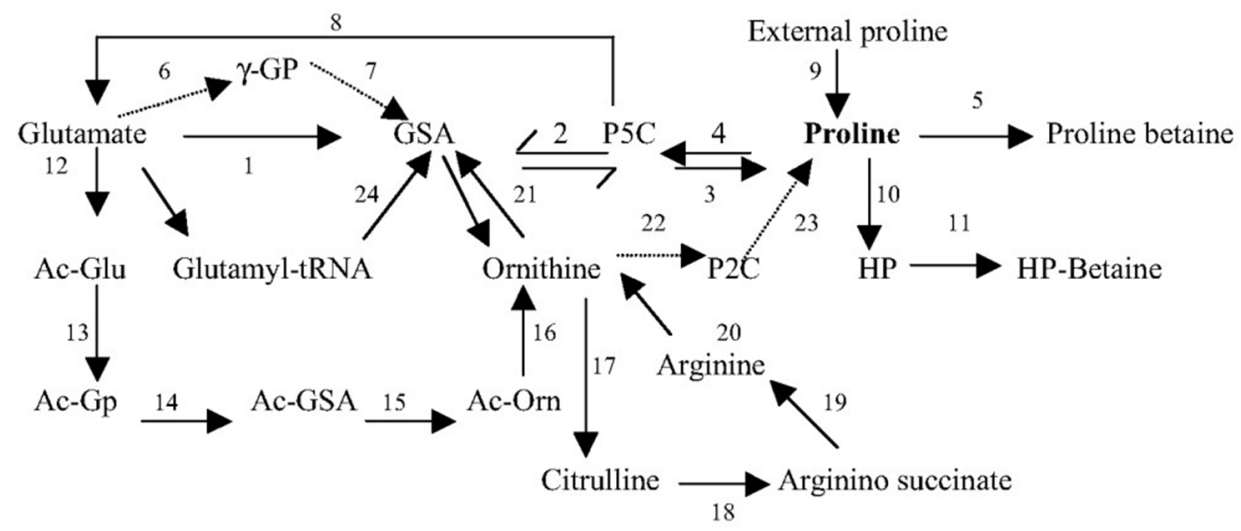

Fig. 1. Plant Proline biosynthesis and degradation pathways (Kavi Kishor et al. 2005).

In previous studies, the $P 5 \mathrm{cs}$ and $O a t$ genes of plants decreased in response to salinity and alkalinity stress. In the present study, P5cs (RpP5cs) and Oat (RpOat) from R. patientia L. were cloned based on transcriptome data (SRP11657). The molecular characterization of RpP5CS and RpOAT protein sequences were predicted, e.g. conserved domain subcellular localization, threedimensional (3D) structure, etc. The expression pattern of RpP5cs and RpOat were analyzed in response to salinity and alkalinity treatments in Щавель Чемпион (L.) and Chinese Rumex patientia $\times R$. tianschanicus $\mathrm{cv}$. Rumex over a period of $24 \mathrm{hrs}$. These results could provide insights into sequence structure and differential tolerance in many plants.

\section{Materials and Methods}

Rumex patientia seeds were collected from Russian Щавель Чемпион (L) and Chinese Rumex patientia $\times R$. tianschanicus cv. Rumex (as control). All seeds were grown in Northeast Agricultural University with a photoperiod of $16 / 8 \mathrm{hrs}$ at $24 \pm 2^{\circ} \mathrm{C}$. The $R$. patientia plants were stressed with $\mathrm{Na}_{2} \mathrm{CO}_{3}: \mathrm{NaHCO}_{3}=1: 1$ at a concentration $80 \mathrm{mmol} / \mathrm{l}$ at two leaves stage. In accordance with the previous study (Liu et al. 2017), all plants were transferred to treatment for 0 , $3,6,12$, or $24 \mathrm{hrs}$ as the experimental group. For the three replicates, $0.1 \mathrm{~g}$ entire seedings were extracted and quickly transferred to liquid nitrogen for $10 \mathrm{~min}$. The samples were stored at $-80^{\circ} \mathrm{C}$. Trace archives for Rumex patientia L. transcriptome data (SRP11657) were searched using the "Cross-species Mega BLAST" on the Nucleotide BLAST website, all known P5cs and Oat sequences in plants were used as BLAST queries under default parameters. The conserved domain 
was predicted using the NCBI conserved domain (http://www.ncbi.nlm.nih.gov/Structure/cdd/ wrpsb.cgi ).

The PCR primers for RpP5cs and RpOat genes were designed based on unigenes data presented in Table 1 . The PCR conditions for the RpP5cs gene were $95^{\circ} \mathrm{C} 5$ min. followed by 35 cycles of $95^{\circ} \mathrm{C} 30 \mathrm{sec}$., $50^{\circ} \mathrm{C} 35 \mathrm{sec}$., and $72^{\circ} \mathrm{C} 150 \mathrm{sec}$., the final extension was $72^{\circ} \mathrm{C}$ for $8 \mathrm{~min}$. The PCR conditions for the RpOat gene were $95^{\circ} \mathrm{C} 5 \mathrm{~min}$. followed by 35 cycles of $95^{\circ} \mathrm{C} 30 \mathrm{~s}$, $53^{\circ} \mathrm{C} 35 \mathrm{sec}$, and $72^{\circ} \mathrm{C} 90 \mathrm{~s}$, the final extension was $72^{\circ} \mathrm{C} 8$ min. The $2178 \mathrm{bp}$ PCR product for RpP5cs and 1401 bp PCR product for RpOat were then subcloned into the pEAST-T3 cloning vector (TransGen Biotech) and sequenced.

Table 1. The cloning primers of RpP5cs and RpOat genes.

\begin{tabular}{ll}
\hline Name & Sequence (from 5' to $3^{\prime}$ ) \\
\hline RpP5cs forward primer & ATGGACTCCATGGATGCGTC \\
RpP5cs reverse primer & TCATGCCATTTTTACTGTTGTTAAG \\
RpOat forward primer & ATGTTAACCAAGCGACTCTTC \\
RpOat reverse primer & TCAAATTTCCCGCCCAC \\
\hline
\end{tabular}

The physicochemical characteristics of the identified protein sequence of RpP5cs and RpOat genes, e.g., amino acids (aa) composition, molecular weight (MW), and isoelectric point (pI) were analyzed using ExPASy (http://web.expasy.org/compute_pi/) (Sperandeo et al. 2005). Modeling of $R p P 5 c s$ and RpOat genes was performed using SWISS-MODEL (https://swissmodel. expasy.org). N-glycosylation and O-glycosylation sites were evaluated using the following weblinks such as http://www.cbs.dtu.dk/services/NetOGlys and http://www.cbs.dtu.dk/services/ NetNGlys, respectively. Protein transmembrane regions were analyzed using http://www. ch.embnet.org/software/TMPRED_form.htmL. Protein phosphorylation sites, N-acetaminophen (GlcNAc) protein modification sites, sumoylation modification sites, tyrosine sulfation sites of proteins and subcellular localization were examined with http://www.cbs.dtu.dk/services/NetPhos; http://www.cbs.dtu.dk/ services/YinOYang/; http://www.abgent.com/sumoplot; http://sulfosite. mbc.nctu.edu.tw/1.0/; and http://www.softberry.com/berry.phtmL?topic=protcompan\&group= programs \& subgroup=proloc. Hydrophobicity and hydrophilicity of proteins were predicted using http://web.expasy.org/protscale/.

The alignment of RpP5cs amino acid sequences and 39 homologues protein sequence in other species were performed using Clustal Omega, results were colour coded. Phylogenetic trees of the Clustal results were constructed using the neighbor-joining (NJ) method (MEGA6.0) (Tamura et al. 2013) using p-distance and complete deletion option parameters, and ascertained using bootstrapping methods with 1000 replicates. Multiple sequence alignment of amino acid sequences from RpOat and 11 other homologues genes were performed using the Clustal Omega, and the methods of phylogenetic trees were constructed as for the RpP5cs genes.

Total RNA was extracted from the samples with Trizol reagent (TransGen Biotech) and quantified with Nanophotometer ${ }^{\mathrm{TM}}$ Pearl (Implen GmbH, Munich, Germany). RNA with OD260/280 $\geq 1.8$ and the concentration $\geq 100 \mathrm{ng} / \mu \mathrm{l}$ was selected for the following experiment. The cDNA strand was synthesized using cDNA Synthesis SuperMix (TransGen Biotech) according to the manufactures' instructions. Gene-specific primers were designed (Table 2). One denaturation cycle was performed at $95^{\circ} \mathrm{C} 5 \mathrm{~min}$, the qRT-PCR cycle was as follows for 40 
amplification cycles: $95^{\circ} \mathrm{C} / 30 \mathrm{sec} ; 40$ cycles of $95^{\circ} \mathrm{C} / 5 \mathrm{sec}$, and $60^{\circ} \mathrm{C} / 30 \mathrm{sec}$. Each treatment was repeated at least three times independently, the $\beta$-actin gene was used as an internal control.

Table 2. Primer sequences for RpP5cs and RpOat genes for qRT-PCR.

\begin{tabular}{ll}
\hline Name & Sequence $\left(5^{\prime}-3^{\prime}\right)$ \\
\hline RpP5cs forward primer & TGGATACGAAGAATCACTTGTAGC \\
RpP5cs reverse primer & AGAAGCAATCTGAACTAAGGCATC \\
RpOat forward primer & TTATACCTGTCAGTGCTGTTCTTG \\
RpOat reverse primer & ATCCCTTAGTTCTTCTCCCATTC \\
$\beta$-actin forward primer & GCTCATCCTGTCGGCAATAC \\
$\beta$-actin reverse primer & ACGAGACTACCTACAACTCCATC \\
\hline
\end{tabular}

All experiments were repeated at least three times. Statistical analyses and graph were performed using Microsoft Excel 2007 (Microsoft, USA). Each column means \pm SE for three biological replicates ( $>3$ ), Different letters indicated significant differences control and samples at time $(\mathrm{P}<0.05)$.

\section{Results and Discussion}

Plant proline accumulation plays key roles in response to various stresses. The proline synthesis pathway can be divided into two species: glutamate pathway and ornithine pathway, P5CS and OAT are key enzymes in plants (Kavi Kishor et al. 2005). The RpP5cs and RpOat genes were identified using Blast 2.3 software by comparison to Rumex patientia L. transcriptome data (SRP11657). Sequences c61543_g1 and c75855_g1_i1 were selected as P5cs and Oat genes. The predicted conserved domains are shown in Fig 2, sequence c61543_g1 was predicted to be delta-1-pyrroline-5-carboxylate synthase and c75855_g1_i1 was predicted to be ornithine-deltaaminotransferase, the predicted results were similar to NCBI published gene results.

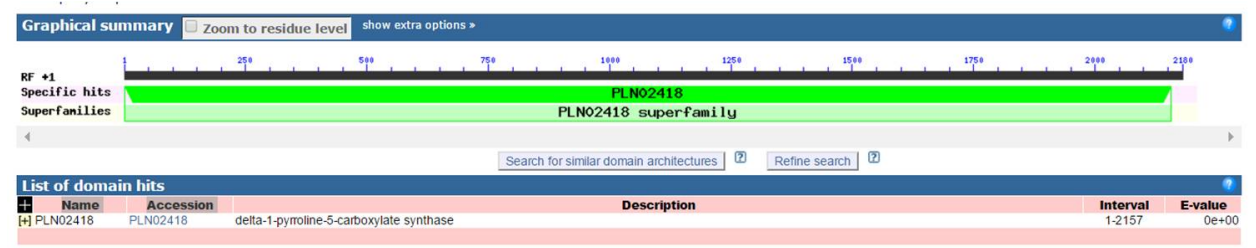

a

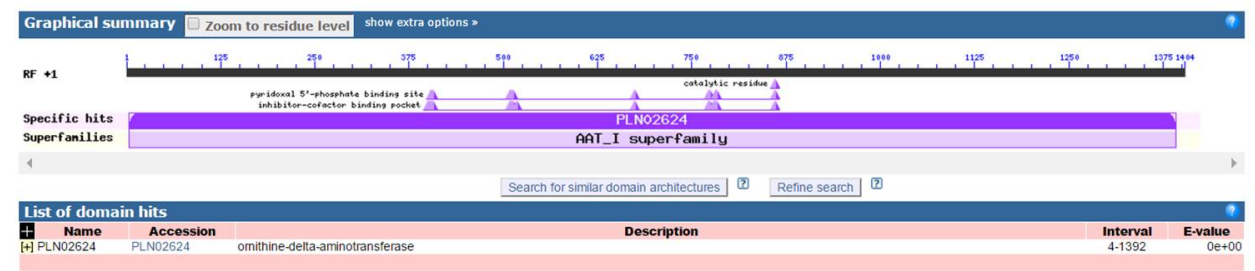

b

Fig. 2. The predicted conserved domains results of selected RpP5cs and RpOat genes. a. The predicted conserved domains results of selected RpP5cs genes; b. The predicted conserved domains results of selected RpOat genes. 
The sequences of c61543_g1 and c75855_g1_i1 were used to design the gene specific primers, the homologous genes were amplified from $R$. patientia plants. Genes were predicted using BLASTN and conserved domain, then named RpP5cs and RpOat (Fig. 3). These results showed the open reading frame (ORF) of the RpP5cs gene contained 2178 nucleotides (bp) encoding 725 aa and the RpOat ORF contained 1401 nucleotides (bp) encoding 466 aa with sequencing. P5cs genes have been cloned from Arabidopsis thaliana (Thompson et al. 1997), Brassica napus (Kubala et al. 2015), Phaseolus vulgaris (Chen et al. 2013), Medicago truncatula (Armengaud et al. 2004) and other species (Armengaud et al. 2004, Su et al. 2011). Oat genes were sequenced in many species, e.g. Vigna aconitifolia (Delauney et al. 1993), other species (Hervieu et al. 1995), Arabidopsis thaliana (Nancy et al. 2002)

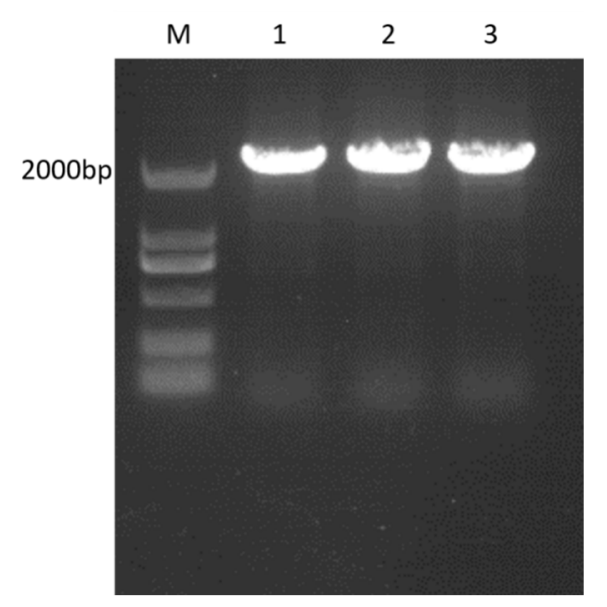

a

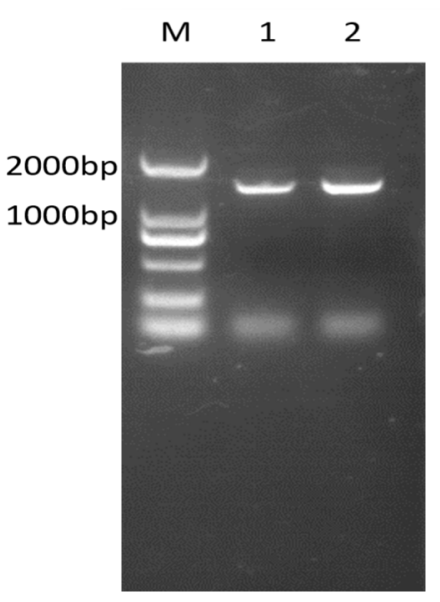

b

Fig. 3. Cloning of RpP5cs and RpOat genes. a. Cloning of RpP5cs gene; b. Cloning of RpOat gene.

The molecular characteristics of RpP5cs were predicted using the ProtParam tool and are shown in Table 3, the results showed 725 amino acids, molecular weight of 177916.65, pI $=4.95$, and the formula was $\mathrm{C}_{6578} \mathrm{H}_{10980} \mathrm{~N}_{2178} \mathrm{O}_{2776} \mathrm{~S}_{403}$. The RpP5CS protein was hydrophobic according to Protscale software. The RpP5CS protein had two kinds of transmembrane domains including 64 inside-outside transmembrane domains and 64 outside-inside transmembrane domains, which were located in the mitochondria. RpP5CS had $95 \mathrm{O}$-glycosylation sites and $23 \mathrm{~N}$-glycosylation sites using NetNGlyc and NetOGlyc. It was also predicted to have 66 protein kinase phosphorylation sites including 39 serine phosphorylation sites, 18 threonine phosphorylation sites, and five tyrosine phosphorylation sites with NetPHos 3.1 Server, which also predicted seven OGlcNAc glycosylated sites, seven small ubiquitin-like modifier sites, and three sulfation sites, when the three-dimensional model of RpP5CS protein was constructed using SWISS-MODEL software (Fig. 4a).

Table 3. The molecular characteristics of RpP5cs and RpOat genes.

\begin{tabular}{lllll}
\hline Gene name & Amino acids & Molecular weight & pI & Formula \\
\hline RpP5cs & 725 & 177916.65 & 4.95 & $\mathrm{C}_{6578} \mathrm{H}_{10980} \mathrm{~N}_{2178} \mathrm{O}_{2776} \mathrm{~S}_{403}$ \\
RpOat & 466 & 51242.5 & 7.86 & $\mathrm{C}_{4217} \mathrm{H}_{7035} \mathrm{~N}_{1401} \mathrm{O}_{1772} \mathrm{~S}_{275}$ \\
\hline
\end{tabular}




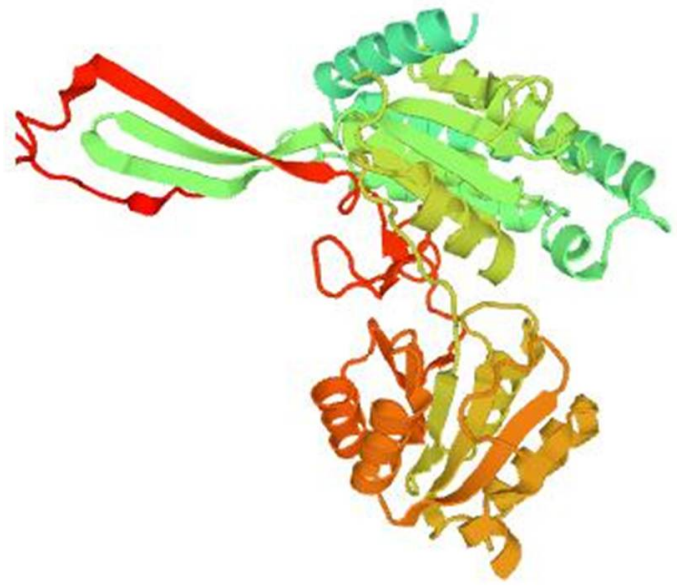

$\mathbf{a}$

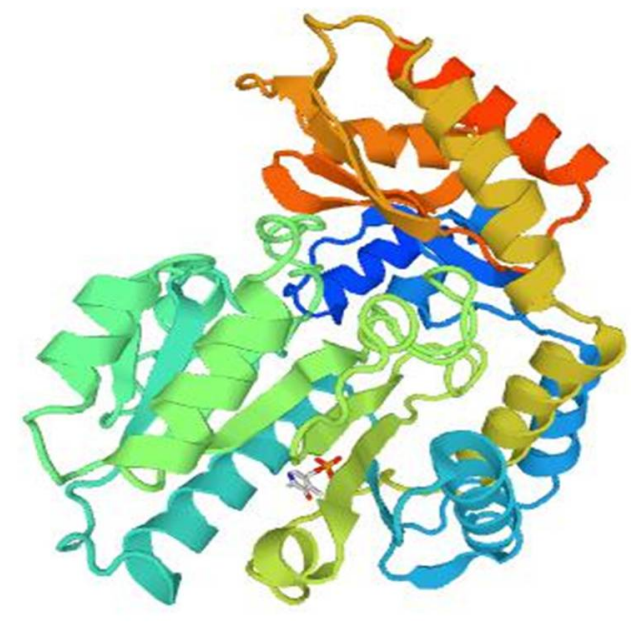

b

Fig. 4. Tertiary structure prediction of proteins for RpP5cs and RpOat genes. a. Tertiary structure prediction of $R p P 5 c s$ gene protein; b. Tertiary structure prediction of RpOat gene protein.

The molecular characteristics of RpOat were predicted using the ProtParam tool and are shown in Table 3, the results showed 466 amino acids, molecular weight of 51242.5, pI = 7.86, and the formula was $\mathrm{C}_{4217} \mathrm{H}_{7035} \mathrm{~N}_{1401} \mathrm{O}_{1772} \mathrm{~S}_{275}$. The RpOAT protein was hydrophobic according to Protscale software. The RpOAT protein had two kinds of transmembrane domains including 42 inside-outside transmembrane domains and 39 outside-inside transmembrane domains, which were located in the mitochondria or cytoplasm. RpOAT had 95 O-glycosylation sites and $12 \mathrm{~N}$ glycosylation sites using NetNGlyc and NetOGlyc. It was also predicted to have 30 protein kinase phosphorylation sites including 19 serine phosphorylation sites, seven threonine phosphorylation sites, and four tyrosine phosphorylation sites with NetPHos 3.1 Server, which predicted seven OGlcNAc glycosylated sites, nine small ubiquitin-like modifier sites and one sulfation site (Fig S11b), when the three-dimensional model of RpP5CS protein was constructed using SWISSMODEL software (Fig. 4b).

The best sequences from BLAST search were used to generate two phylogenetic trees (Fig. 5). The results showed the P5cs protein of $R$. patientia, Salicornia bigelovii (sea tent) and Mesembryanthemum crystallinum (published in Genbank) clustured on a single branch of the tree, and was distinct from other plants; the R. patientia and Solanum lycopersicum (tomato) gene were clustered on the same evolutionary branch, which was distinct from 11 other species.

RpP5CS protein domain analysis showed the presence of two conserved domains including AAK superfamily accession number CD04256 and ALDH_F18-19_Pro-GPR accession number CD07079. RpOAT protein domain analysis showed one conserved domain in AAT_I superfamily, with Pfam accession number PLN02624 as reported earlier (Ramadan and Hassanein 2014, Marchler-Bauer et al. 2017). RpP5CS was located in mitochondria and RpOAT was located in mitochondria or cytoplasm (Nancy et al. 2002, Ramadan and Hassanein 2014). Based on the above analyses, characteristic analysis of RpP5cs and RpOat genes were predicted and phylogenetic analyses were constructed to provide a theoretical basis for future studies. 


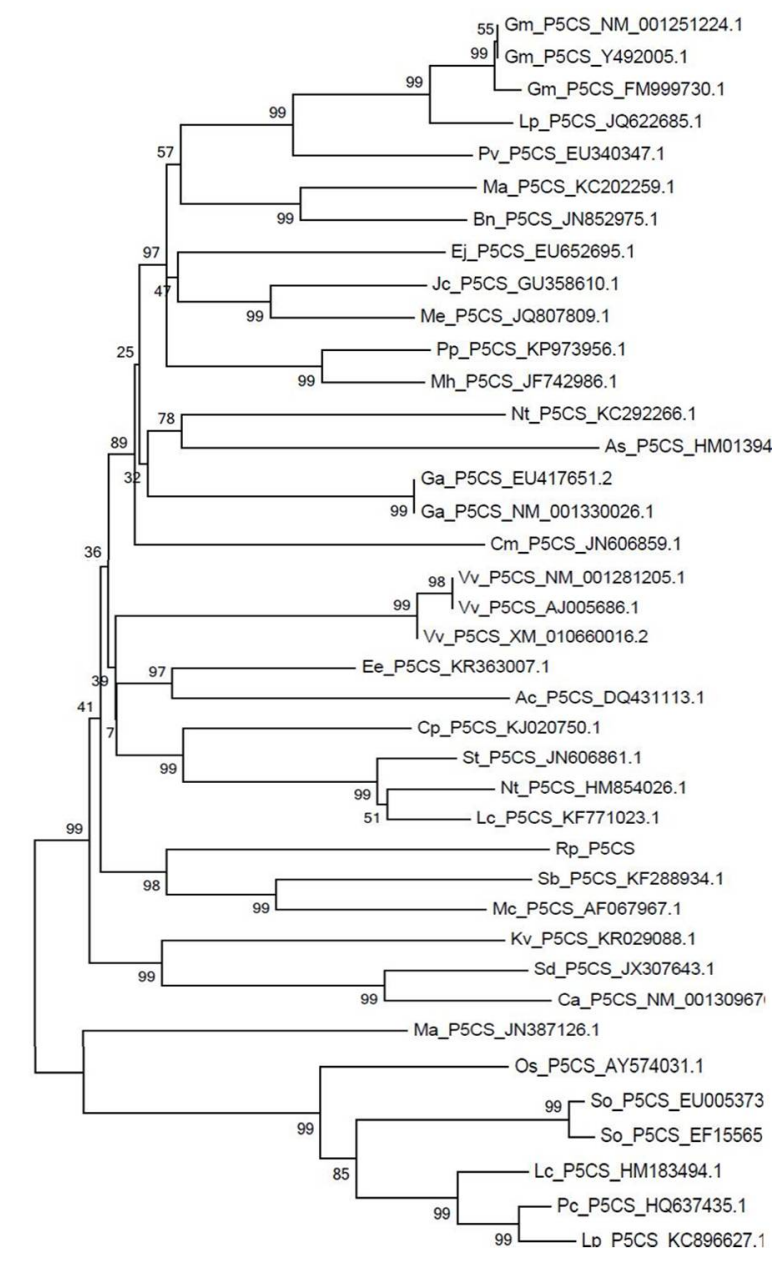

a

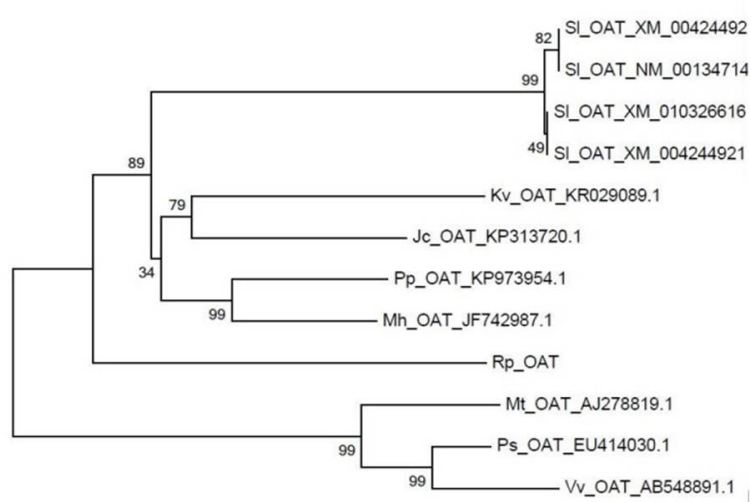

b

Fig. 5. Phylogenetic trees constructed with MEGA6 based on the amino acids of the RpP5cs and RpOat genes from different plant species. a. RpP5cs gene; b. RpOat gene. 
The expression of RpP5cs and RpOat genes in Russian Щавель Чемпион (L) and Chinese Rumex patientia $\times R$. tianschanicus $\mathrm{cv}$. Rumex (as control) were challenged with salinity and alkalinity stress, the results showed the expression of RpP5cs genes were higher in Russian Щавель Чемпион than Chinese Rumex patientia $\times R$. tianschanicus cv. Rumex, and the expression of RpP5cs gene was highest in Russian Щавель Чемпион at $6 \mathrm{~h}$; the expression of $R p P 5 c s$ was down-regulated in Chinese Rumex patientia $\times$ R. tianschanicus cv. Rumex (Fig. 6a). The expression of RpOat gene first increased and then decreased in Russian Щавель Чемпион (L.), and the expression of RpOat was highest in Russian Щавель Чемпион at $12 \mathrm{hrs}$, the expression of RpOat was higher in Russian Щавель Чемпион than Chinese Rumex patientia $\times R$. tianschanicus cv. Rumex. The results suggest Russian Щавель Чемпион could be more resistant to salt and alkalinity compared with Chinese Rumex patientia $\times R$. tianschanicus $\mathrm{cv}$. Rumex (Fig. $6 b)$. The results showed that Russian Щавель Чемпион (L) is a resistant species to the salt and alkalinity.
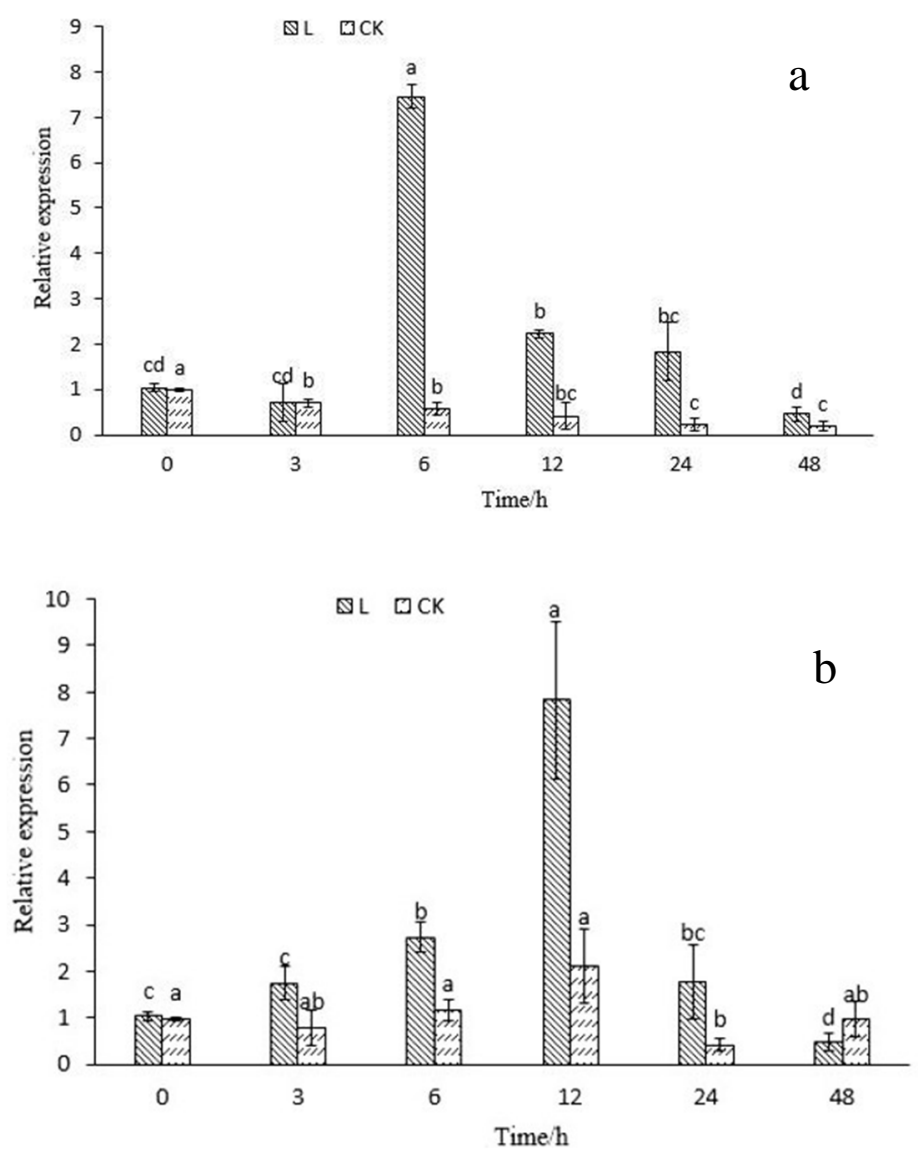

Fig 6 Relative expression of RpP5cs and RpOat genes under complex saline-alkali conditions. a. Relative expression of RpP5cs gene under complex saline-alkali conditions; b. Relative expression of RpOat gene under complex saline-alkali conditions. L show Russian Щавель Чемпион; CK represented Chinese Rumex patientia $\times R$. tianschanicus cv. Rumex. Oh as control. Each column means $\pm \mathrm{SE}$ for three biological replicates $(n>3)$. Different letters indicated significant differences control and samples at time $(\mathrm{p}<0.05)$. 
Expression of RpP5cs and RpOat genes could be changed by various abiotic stresses. The expression of $N t P 5 \mathrm{cs}$ gene was induced by salt, dehydration, and temperature stress (Zheng et al. 2014). Over-expression of PvP5cs 1 and PvP5cs2in Arabidopsis increased proline production and salt tolerance (Chen et al. 2013). OAT activity was increased with salt treatment, the expression of AtOat gene increased after exposure to $200 \mathrm{mM} \mathrm{NaCl}$ (Canas et al. 2008). Radish (Raphanus sativus) seedlings using the OAT inhibitor demonstrated the contribution of the ornithine pathway to proline synthesis under $\mathrm{NaCl}$ treatment (Hervieu et al. 1995). In previous studies, the P5cs and Oat genes of plants decreased under salinity and alkalinity treatment. In the present study, the expression of RpP5cs and RpOat genes were higher in Russian Щавель Чемпион than Chinese Rumex patientia $\times R$. tianschanicus $\mathrm{cv}$. Rumex under salinity and alkalinity treatment over $24 \mathrm{hrs}$. The results suggest Russian Щавель Чемпион could be more resistant to salt and alkalinity compared with Chinese Rumex patientia $\times R$. tianschanicus cv. Rumex, as the expression of P5cs and Oat genes was measured to determine the capability to respond to various abiotic stresses.

\section{Acknowledgments}

This research was funded by Research and Development Project of Applied Science and Technology in Harbin (2015RAQXJ021) and National International Science and Technology Cooperation (2013DFR30270).

\section{References}

Adams E and L Frank 1980. Metabolism of proline and the hydroxyprolines. Ann. Rev. Biochem. 49: 10051061.

Armengaud P, L Thiery, N Buhot, MG Grenier-De and A Savoure 2004. Transcriptional regulation of proline biosynthesis in Medicago truncatula reveals developmental and environmental specific features. Physiol. Plant 120: 442-450.

Canas RA, DP Villalobos, SM Diaz-Moreno, FM Canovas and FR Canton 2008. Molecular and functional analyses support a role of Ornithine- $\{$ delta $\}$-aminotransferase in the provision of glutamate for glutamine biosynthesis during pine germination. Plant Physiol. 148: 77-88.

Chen JB, JW Yang, ZY Zhang, XF Feng and SM Wang 2013. Two P5CS genes from common bean exhibiting different tolerance to salt stress in transgenic Arabidopsis. J. Genet. 92: 461-9.

Delauney AJ, CA Hu, PB Kishor and DP Verma 1993. Cloning of ornithine delta-aminotransferase cDNA from Vigna aconitifolia by trans-complementation in Escherichia coli and regulation of proline biosynthesis. J. Biol. Chem. 268: 18673-18678.

Ghanti SKK, KG Sujata, BMV Kumar, NN Karba, KJ Reddy, MS Raoa and PB Kavi Kishor 2011. Heterologous expression of P5CS gene in chickpea enhances salt tolerance without affecting yield. Biol. Plantarum 55: 634-640.

Hervieu FLDL, C Huault and JP Billard 1995. Contribution of ornithine aminotransferase to proline accumulation in NaCl-treated radish cotyledons. Plant Cell Environ. 18: 205-210.

Hu CA, AJ Delauney and DP Verma 1992. A bifunctional enzyme ( $\Delta^{1}$-pyrroline-5-carboxylate synthetase) catalyzes the first two steps in proline biosynthesis in plants. Proc. Natl. Acad. Sci., USA 89: 9354-358.

Igarashi Y, Y Yoshiba, Y Sanada, K Yamaguchi-Shinozaki, K Wada and K Shinozaki 1997. Characterization of the gene for delta1-pyrroline-5-carboxylate synthetase and correlation between the expression of the gene and salt tolerance in Oryza sativa L. Plant Mol. Bio. 33: 857-65.

Kavi Kishor PB, S Sangam, RN Amrutha, P Sri Laxmi and N Sreenivasulu 2005. Regulation of proline biosynthesis, degradation, uptake and transport in higher plants: Its implications in plant growth and abiotic stress tolerance. Curr. Sci. India 88: 424-38. 
Kubala S, L Wojtyla, M Quinet, K Lechowska, S Lutts and M Garnczarska 2015. Enhanced expression of the proline synthesis gene P5CSA in relation to seed osmopriming improvement of Brassica napus germination under salinity stress. Plant Physiol. 183: 1-12.

Li JM, LP Hu, L Zhang, XB Pan and XH Hu 2015. Exogenous spermidine is enhancing tomato tolerance to salinity-alkalinity stress by regulating chloroplast antioxidant system and chlorophyll metabolism. BMC Plant Biol. 15: 303.

Liu JX, YQ Xu, LG Zhang, W Li, ZX Cai, F Li, P Mu, FL Li and BZ Hu 2017. Correction: De novo assembly and analysis of the transcriptome of Rumex patientia L. during cold stress. PloS One 12: e0186470.

Marchler-Bauer A, Y Bo, L Han, J He, CJ Lanczycki, S Lu, F Chitsaz, MK Derbyshire, RC Geer, NR Gonzales, M Gwadz, DI Hurwitz, F Lu, GH Marchler, JS Song, N Thanki, ZX Wang, RA Yamashita, DC Zheng, LY Geer and SH Bryant 2017. CDD/SPARCLE: functional classification of proteins via subfamily domain architectures. Nucleic Acids Res. 45: D200-D03.

Namgail T, JL Fox and YV Bhatnagar 2007. Carnivore-caused livestock mortality in Trans-Himalaya. Environ. Manage. 39: 490-496.

Nancy HR, AB Fawaz, L Kristof, A Geert and J Michel 2002. Overexpression of ornithine- $\delta$ aminotransferase increases proline biosynthesis and confers osmotolerance in transgenic plants. Mol. Breeding 9: 73-80.

Peng LN, YQ Xu, X Wang, X Feng, QQ Zhao, SS Feng, ZY Zhao, BZ Hu and FL Li 2019. Overexpression of paralogues of the wheat expansin gene TaEXPA8 improves low-temperature tolerance in Arabidopsis. Plant Biol. 21: 1119-1131.

Peng LN, YQ Xu, X Feng, JF Zhang, JM Dong, SK Yao, Z Feng, QQ Zhao, SS Feng, FL Li and BZ Hu 2020. Identification and characterization of the expansin genes in Triticum urartu in response to various phytohormones. Russian J. Genet. 56: 441-453.

Qi X, E Wang, M Xing, W Zhao and X Chen 2012. Rhizosphere and non-rhizosphere bacterial community composition of the wild medicinal plant Rumex patientia. World J. Microbiol. Biotechnol. 28: 2257-65.

Ramadan AM and SE Hassanein 2014. Characterization of P5CS gene in Calotropis procera plant from the de novo assembled transcriptome contigs of the high-throughput sequencing dataset. Comptes Rendus. Biolog. 337: 683-90.

Serrano R 1996. Salt tolerance in plants and microorganisms: toxicity targets and defense responses. Int. Rev. Cytol. 165: 1-52.

Singh N, JS Arya, SB Maurya, RB Srivastava 2013. Rumex (Rumex patientia L.) - spinach of high-altitude cold desert. Curr. Sci. 104: 574.

Sperandeo MP, P Annunziata, V Ammendola, V Fiorito, A Pepe, MV Soldovieri, T Maurizio, A Generoso and S Gianfranco 2005. Lysinuric protein intolerance: identification and functional analysis of mutations of the SLC7A7 gene. Human Mutation 25: 410.

Su M, XF Li, XY Ma, XJ Peng, AG Zhao, LQ Cheng, SY Chen and GS Liu 2011. Cloning two P5CS genes from bioenergy sorghum and their expression profiles under abiotic stresses and MeJA treatment. Plant Sci. 181: 652-659.

Tamura K, G Stecher, D Peterson, A Filipski and S Kumar 2013. MEGA6: molecular evolutionary genetics analysis version 6.0. Mol. Biol. Evol. 30: 2725-9.

Thompson WF, AF Beven, B Well and PJ Shaw 1997. Differential expression of two P5CS genes controlling proline accumulation during salt-stress requires $\mathrm{ABA}$ and is regulated by $A B A 1, A B I 1$ and $A X R 2$ in Arabidopsis. Plant J. 12: 557-569.

Vendruscolo EC, I Schuster, M Pileggi, CA Scapim, HB Molinari, CJ Marur and LGE Vieira 2007. Stressinduced synthesis of proline confers tolerance to water deficit in transgenic wheat. Plant Physiol. 164: 1367-1376.

Verbruggen N and C Hermans 2008. Proline accumulation in plants: a review. Amino Acids 35: 753-759. 
Wang ZQ, YZ Yuan, JQ Ou, QH Lin QH and CF Zhang 2007. Glutamine synthetase and glutamate dehydrogenase contribute differentially to proline accumulation in leaves of wheat (Triticum aestivum) seedlings exposed to different salinity. J. Plant Physiol. 164: 695-701.

Wu LQ, ZM Fan, L Guo, YQ Li, WJ Zhang, LJ Qu and ZL Chen 2003. Over-expression of an Arabidopsis delta-OAT gene enhances salt and drought tolerance in transgenic rice. Chinese Sci. Bull. 48: 2594-2600.

Zheng L, Z Dang, H Li, H Zhang, S Wu and Y Wang 2014. Isolation and characterization of a Delta1pyrroline-5-carboxylate synthetase (NtP5CS) from Nitraria tangutorum Bobr. and functional comparison with its Arabidopsis homologue. Mol. Biol. Reports 41: 563-572.

(Manuscript received on 19 May, 2021; revised on 20 August, 2021) 